\title{
Susceptibility of coagulase-negative staphylococci to a kanamycin and cefalexin combination
}

\author{
P. Silley, ${ }^{*} \dagger^{1}$ L. Goby, $\ddagger$ and C. M. Pillar§ \\ *MB Consult Limited, Southampton, SO14 3XB, United Kingdom \\ †University of Bradford, Bradford, BD7 1DP, United Kingdom \\ łBoehringer Ingelheim Animal Health GmbH, Ingelheim, Germany 55216 \\ §Eurofins Medinet, Chantilly, VA 20151
}

\begin{abstract}
A combination of kanamycin and cefalexin was licensed in Europe in 2008 to treat bovine clinical mastitis. Preliminary broth and disk clinical breakpoints for this antibiotic combination have been proposed for Staphylococcus aureus, Streptococcus dysgalactiae, Streptococcus uberis, and Escherichia coli. This study indicates that these proposed breakpoints also hold for coagulase-negative staphylococci (CNS), a group of bacteria frequently isolated in milk samples from cows with clinical mastitis. The data show that clinical bovine mastitis isolates of CNS from Europe have a high degree of susceptibility to the kanamycin/cefalexin combination, with minimal resistance to either agent alone. The use of the available kanamycin and cefalexin combination disk for testing the susceptibility of bovine mastitis isolates of Staph. aureus, Strep. uberis, Strep. dysgalactiae, and E. coli is also reliable for use in the testing of CNS, as disk results correlated with broth minimum inhibitory concentrations. The study reports, for the first time, the approved Clinical Laboratory Standards Institute quality control ranges for the kanamycin/cefalexin combination and wild-type cutoff values for major bacterial pathogens implicated in bovine mastitis.
\end{abstract}

Key words: cefalexin, kanamycin, mastitis, coagulasenegative staphylococci

\section{INTRODUCTION}

Cefalexin is a first-generation cephalosporin that can be effectively combined with the aminoglycoside kanamycin to treat bovine clinical mastitis. A combination of the 2 active ingredients was licensed in Europe in 2008 as Ubrolexin (Boehringer Ingelheim Animal Health, Ingelheim, Germany) for intracisternal administration directly into the udder of infected cows

Received October 10, 2011.

Accepted February 2, 2012

${ }^{1}$ Corresponding author: p-s@mbconsult.co.uk in a kanamycin:cefalexin ratio of 1:1.5 (wt/wt). This combination offers an extended spectrum of activity compared with that of each individual drug. The 2 antimicrobials have been shown to demonstrate synergy against major mastitis pathogens such as Staphylococcus aureus, Streptococcus uberis, and Escherichia coli, offering potential for increased efficacy compared with using either of the antibiotics alone (Ganiere and Denuault, 2009; Maneke et al., 2011). Combination therapy can also be useful in situations in which resistance of a particular target pathogen to one agent has emerged but susceptibility to the other agent persists (Pillar et al., 2009).

Pillar et al. (2009) evaluated the appropriate broth microdilution testing criteria for kanamycin and cefalexin administered in combination and reported on the development of a disk diffusion test. In the absence of Clinical and Laboratory Standards Institute (CLSI) published interpretive criteria, little information exists on how to test for the in vitro susceptibility of kanamycin and cefalexin in combination against organisms causing mastitis. Based on achievable concentrations in milk and the distribution of MIC, Pillar et al. (2009) proposed preliminary broth breakpoints for kanamycin/cefalexin (10:1 fixed ratio) of $\leq 8 / 0.8 \mu \mathrm{g} /$ $\mathrm{mL}$ susceptible $(\mathbf{S}), 16 / 1.6 \mu \mathrm{g} / \mathrm{mL}$ intermediate $(\mathbf{I})$, and $\geq 32 / 3.2 \mu \mathrm{g} / \mathrm{mL}$ resistant $(\mathbf{R})$ for staphylococci, streptococci, and E. coli. Parallel testing by disk diffusion and error-rate bounded analysis using a combined disk concentration of $30 \mu \mathrm{g}$ of kanamycin and $15 \mu \mathrm{g}$ of cefalexin resulted in the establishment of preliminary disk interpretive breakpoints of $\geq 20 \mathrm{~mm} \mathrm{~S}, 18$ to 19 $\mathrm{mm} \mathrm{I}$, and $\leq 17 \mathrm{~mm} \mathrm{R}$ for Staph. aureus, streptococci (Strep. uberis and Strep. dysgalactiae only), and E. coli. It is important, however, to ascertain if these proposed breakpoints also hold for CNS, as they are considered to be the most prevalent group of bacteria found in bovine milk samples in many parts of the world (Schukken et al., 2009) and have been associated with clinical mastitis cases (Thorberg et al., 2009). Although their clinical relevance is poorly understood in part because of taxonomic issues (Zadoks and Watts, 2009), the CNS 
are considered by many to be true mastitis pathogens (Zhang and Maddox, 2000; Gillespie et al., 2009).

This publication considers new data and shows that the breakpoints proposed by Pillar et al. (2009) for this kanamycin:cefalexin combination can also be applied to CNS.

\section{MATERIALS AND METHODS}

\section{Bacterial Isolates}

In total, 148 CNS field isolates, all from cases of bovine clinical mastitis in Europe, with strains from Germany (47), the UK (40), the Netherlands (27), Belgium (25) and France (9), mostly collected in 2010, were screened alongside 8 strains preselected for kanamycin/ cefalexin resistance from the isolate repository housed at Eurofins Medinet (Chantilly, VA). Interpretation of cefalexin and kanamycin susceptibility was based on established cefoxitin and kanamycin interpretive criteria (CLSI standard M100-S21; CLSI, 2011).

\section{Susceptibility Testing by Broth Microdilution and Disk Diffusion}

All methods were as described previously (Pillar et al., 2009); essentially MIC were determined for all isolates by broth microdilution testing according to CLSI methodology (CLSI standard M31-A3; CLSI, 2009) using commercial frozen panels (Trek Diagnostics, Cleveland, $\mathrm{OH})$. Disks containing $30 \mu \mathrm{g}$ of kanamycin and $15 \mu \mathrm{g}$ of cefalexin were used (Mast Group Ltd., Bootle, $\mathrm{UK})$. Isolates were tested by disk diffusion in parallel with broth microdilution. Quality control (QC) for the broth microdilution and disk diffusion testing of kanamycin and cefalexin individually was performed in accordance with CLSI M31-A3 with Staph. aureus ATCC 29213 (broth) and Staph. aureus ATCC 25923 (disk) as appropriate. The CLSI has evaluated QC data for a 10:1 ratio of kanamycin:cefalexin in a broth microdilution study, and the approved ranges are shown in Table 1.

\section{Evaluation of Interpretive Criteria for Broth Microdilution and Disk Diffusion Testing}

Breakpoints for broth microdilution testing of the combination of 10:1 kanamycin:cefalexin were derived by Pillar et al. (2009) for staphylococci, streptococci, and E. coli based on the MIC distributions of the combination and activity of the individual agents as they relate to the availability of kanamycin and cefalexin in milk after administration. The overall correlation of broth MIC to disk zone size was determined against the
CNS isolates according to CLSI guidelines. The isolates known to be resistant to kanamycin, cefalexin, or both were included to challenge the performance of the disk test. The proposed interpretive criteria described by Pillar et al. (2009) were subjected to error rate bounding to determine whether these criteria are suitable for use when testing CNS.

\section{RESULTS AND DISCUSSION}

The susceptibility of each antimicrobial alone and of kanamycin and cefalexin at a 10:1 ratio against the 148 clinical CNS isolates and the data for the preselected resistant isolates are presented in Table 2 . Of the preselected resistant isolates, $2(25 \%)$ were kanamycin susceptible but cefalexin resistant, 1 (12.5\%) isolate was kanamycin susceptible but cefalexin intermediate, and $5(62.5 \%)$ isolates were resistant to both kanamycin and cefalexin. The proposed breakpoints derived by Pillar et al. (2009) for staphylococci, streptococci, and E. coli were applied to the data for CNS and the numbers of $\mathrm{S}, \mathrm{I}$, and $\mathrm{R}$ are shown in Table 2. The susceptibility distribution for all CNS isolates is shown in Figure 1, also detailing the already proposed breakpoints. Disk diffusion data against the same group of isolates for kanamycin and cefalexin tested alone (both at $30 \mu \mathrm{g}$ ) along with a disk containing $30 \mu \mathrm{g}$ of kanamycin and $15 \mu \mathrm{g}$ of cefalexin is presented in Table 3 , and the zone size distribution shown in Figure 2.

The data can be summarized by considering that $99.3 \%$ of the bovine CNS isolates were susceptible to Ubrolexin (kanamycin combined with cefalexin) by broth microdilution and disk diffusion. One isolate $(0.7 \%)$ was of intermediate susceptibility (Ubrolexin MIC of $16 / 6 \mathrm{mg} / \mathrm{L}$; kanamycin MIC of $>256 \mathrm{mg} / \mathrm{L}$; cefalexin MIC of $2 \mathrm{mg} / \mathrm{L}$ ). Of the field CNS resistant isolates, $1(0.7 \%)$ was resistant to both kanamycin and cefalexin, $3(2 \%)$ were nonsusceptible to cefalexin but susceptible to kanamycin, and $1(0.7 \%)$ was resistant to kanamycin but susceptible to cefalexin. The 5 preselected isolates resistant to both kanamycin and cefalexin were resistant to Ubrolexin, whereas the 3 preselected isolates with differential susceptibility to kanamycin and cefalexin were susceptible to the combination; this may be explained by the fact that they

Table 1. Clinical Standards Laboratory Institute-approved quality control (QC) values for kanamycin/cefalexin

\begin{tabular}{lc}
\hline Organism & QC range $(\mu \mathrm{g} / \mathrm{mL})$ \\
\hline Staphylococcus aureus ATCC 29213 & $1 / 0.1$ to $4 / 0.4$ \\
Escherichia coli ATCC 25922 & $2 / 0.2$ to $8 / 0.8$ \\
Streptococcus pneumoniae ATCC 49619 & $8 / 0.8$ to $64 / 6.4$ \\
\hline
\end{tabular}


were resistant to one but not the other of the drugs in the combination.

The objective of this study was to ascertain whether the proposed breakpoints derived by Pillar et al. (2009) for Staph. aureus, streptococci (Strep. uberis and Strep. dysgalactiae only), and E. coli were also relevant to the CNS. What is clear from Figure 3 is that although we found a low correlation coefficient $(\mathrm{r}=0.51)$, as is sometimes observed when evaluating highly susceptible populations, it was clear from the scatter plot analysis that high MIC were associated with small disk zones, and zones increased along with decreasing MIC values. Error rate bounding analysis of previously established Ubrolexin interpretive criteria $(<8 / 0.8 \mathrm{mg} / \mathrm{L},>20 \mathrm{~mm}$ $=\mathrm{S} ; 16 / 1.6 \mathrm{mg} / \mathrm{L}, 18-19 \mathrm{~mm}=\mathrm{I} ;>32 / 3.2 \mathrm{mg} / \mathrm{L},<17$ $\mathrm{mm}=\mathrm{R}$ ) showed minimal error rates for the evaluated CNS population, with an overall minor error rate of $0.7 \%$ and no very major or major errors. This means that the latter values may tentatively be used to differentiate between field resistant and susceptible populations.

The data provided in the prior and current studies lends itself to describing the wild-type population of mastitis pathogens. Schwarz et al. (2010) considered the categorization of bacterial isolates as susceptible, intermediate, or resistant to tested antimicrobials, making the important point that such classification requires approved interpretive criteria. Currently, 2 types of interpretive criteria are available: clinical breakpoints and epidemiological cut-off values (Bywater et al., 2006). If data are intended to establish which antimicrobial agents are most likely to lead to therapeutic success, then clinical breakpoints must be applied. Epidemiological cut-off values should be used to describe MIC distributions of bacteria without any clinical context.

Analysis of the data derived by Pillar et al. (2009) for Staph. aureus, streptococci (Strep. uberis and Strep. dysgalactiae only), and E. coli suggests that the wild-type population of this group of mastitis pathogens against the kanamycin:cefalexin combination is bounded by a MIC of $8 / 0.8$, whereas that for the CNS is bounded by a MIC of $4 / 0.4$. Clinical breakpoints and epidemiological cut-off values may be very similar or even identical for some bacteria-drug combinations; however, epidemiological cut-off values are determined by a different approach than clinical breakpoints. The term "breakpoint" should be used exclusively for clinical breakpoints and "susceptible," "intermediate," and "resistant" categories should be reserved for classifications made in relation to the therapeutic application of antimicrobial agents. When reporting data using epidemiological cut-off values, the term "resistant" is inappropriate; instead, bacteria should be reported as "wild-type" if the MIC or zone diameter falls within 
Table 3. Susceptibility of bovine CNS to kanamycin and cefalexin alone and in combination by disk diffusion in normal and preselected populations

\begin{tabular}{|c|c|c|c|c|c|c|c|c|c|c|c|c|}
\hline \multirow[b]{2}{*}{ Drug } & \multicolumn{6}{|c|}{ Normal population $^{1}$} & \multicolumn{6}{|c|}{ Preselected population $^{2}$} \\
\hline & Range & Mode & Mean & $\mathrm{S}^{3}$ & I & $\mathrm{R}$ & Range & Mode & Mean & $\mathrm{S}$ & I & $\mathrm{R}$ \\
\hline Kanamycin & 6 to 41 & 27 & 26.8 & $\begin{array}{l}146 \\
(98.6)\end{array}$ & $\begin{array}{l}0 \\
(0.0)\end{array}$ & $\begin{array}{l}2 \\
(1.4)\end{array}$ & 6 to 24 & 6 & 12.6 & $\begin{array}{c}3 \\
(37.5)\end{array}$ & $\begin{array}{l}0 \\
(0.0)\end{array}$ & $\begin{array}{c}5 \\
(62.5)\end{array}$ \\
\hline Cefalexin & 8 to 40 & 30 & 28.4 & $\begin{array}{l}144 \\
(97.3)\end{array}$ & $\begin{array}{c}0 \\
(0.0)\end{array}$ & $\begin{array}{l}4 \\
(2.7)\end{array}$ & 6 to 11 & 6 & 6.9 & $\begin{array}{c}0 \\
(0.0)\end{array}$ & $\begin{array}{c}0 \\
(0.0)\end{array}$ & $\begin{array}{c}8 \\
(100)\end{array}$ \\
\hline
\end{tabular}

${ }^{1}$ CNS field isolates from cases of bovine clinical mastitis in Europe $(\mathrm{n}=148)$.

${ }^{2}$ Population with known resistance $(\mathrm{n}=8)$.

${ }^{3}$ Kanamycin and cefalexin interpreted according to Clinical Standards Laboratory Institute (CLSI) M100-S21 (CLSI, 2011); kanamycin and cefalexin in combination interpreted based on proposed criteria. $\mathrm{S}=$ susceptible, $\mathrm{I}=$ intermediate, $\mathrm{R}=$ resistant; no. $(\%)$.

the wild-type range, or "non-wild-type" if the MIC is higher or the zone diameter smaller than the wild-type range. Indeed, Magiorakos et al. (2011), in an international expert proposal for interim standard definitions for acquired resistance, clearly stated that a bacterial isolate should only be considered nonsusceptible to an antimicrobial agent when it tested resistant, intermediate, or nonsusceptible using clinical breakpoints as interpretive criteria, and not epidemiological cut-offs.
In recent years, the term "epidemiological breakpoints" or "epidemiological cutoff" has been proposed by the European Committee on Antimicrobial Susceptibility Testing to describe the upper MIC limit of the susceptible peak in a MIC distribution, the wild-type population (Kronvall, 2010). A microorganism is defined by the committee as wild type for a particular species according to the absence of acquired and mutational resistance mechanisms to the drug in question

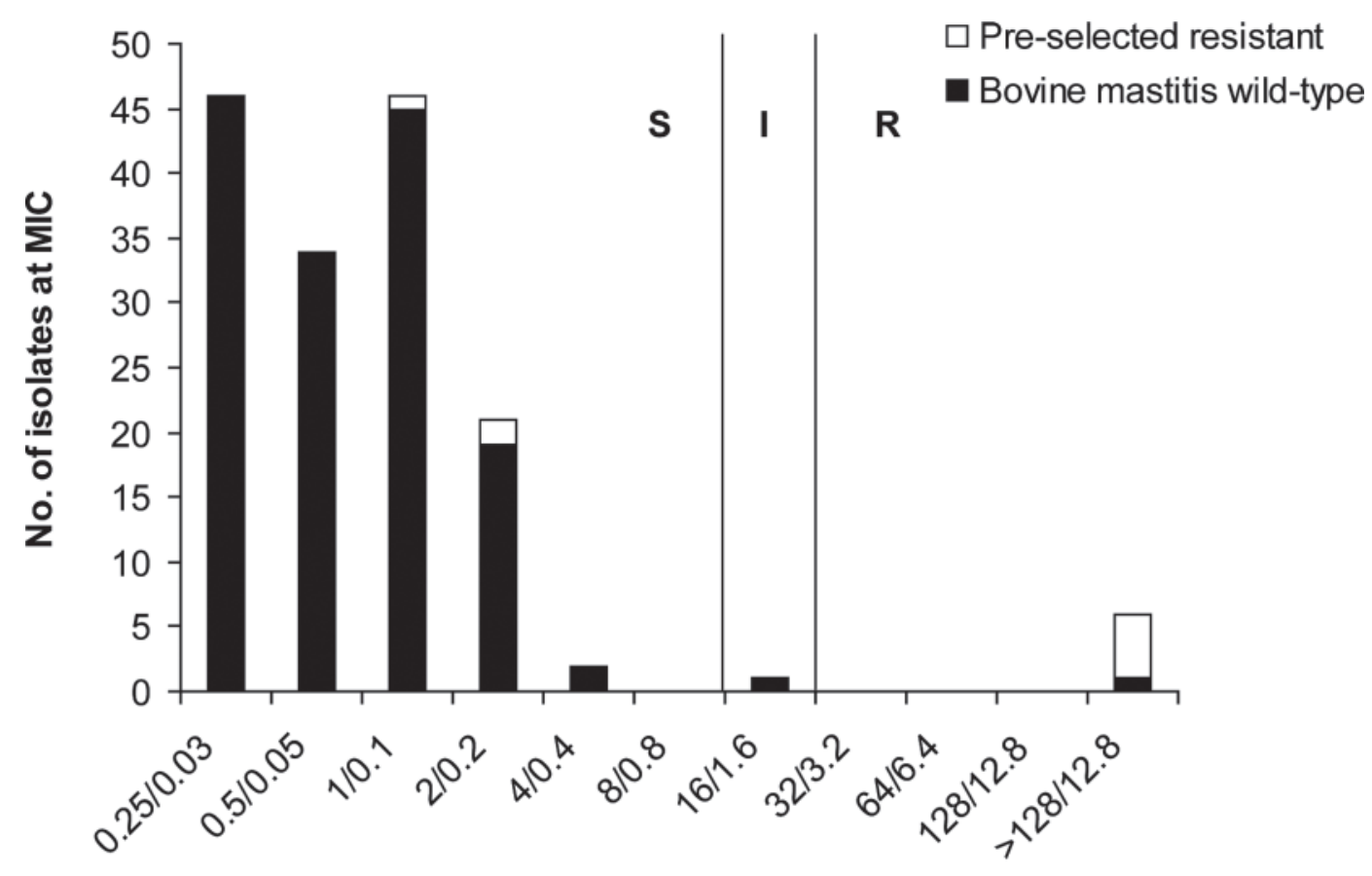

Kanamycin:cefalexin MIC (mg/L)

Figure 1. Distribution of MIC of kanamycin in combination with cefalexin (10:1 fixed ratio) against wild-type bovine mastitis CNS isolates and a subset of CNS isolates preferentially selected for resistance to kanamycin, cefalexin, or both. Applied interpretive criteria were those published by Pillar et al. (2009). $\mathrm{S}=$ susceptible, $\mathrm{I}=$ intermediate, $\mathrm{R}=$ resistant. 


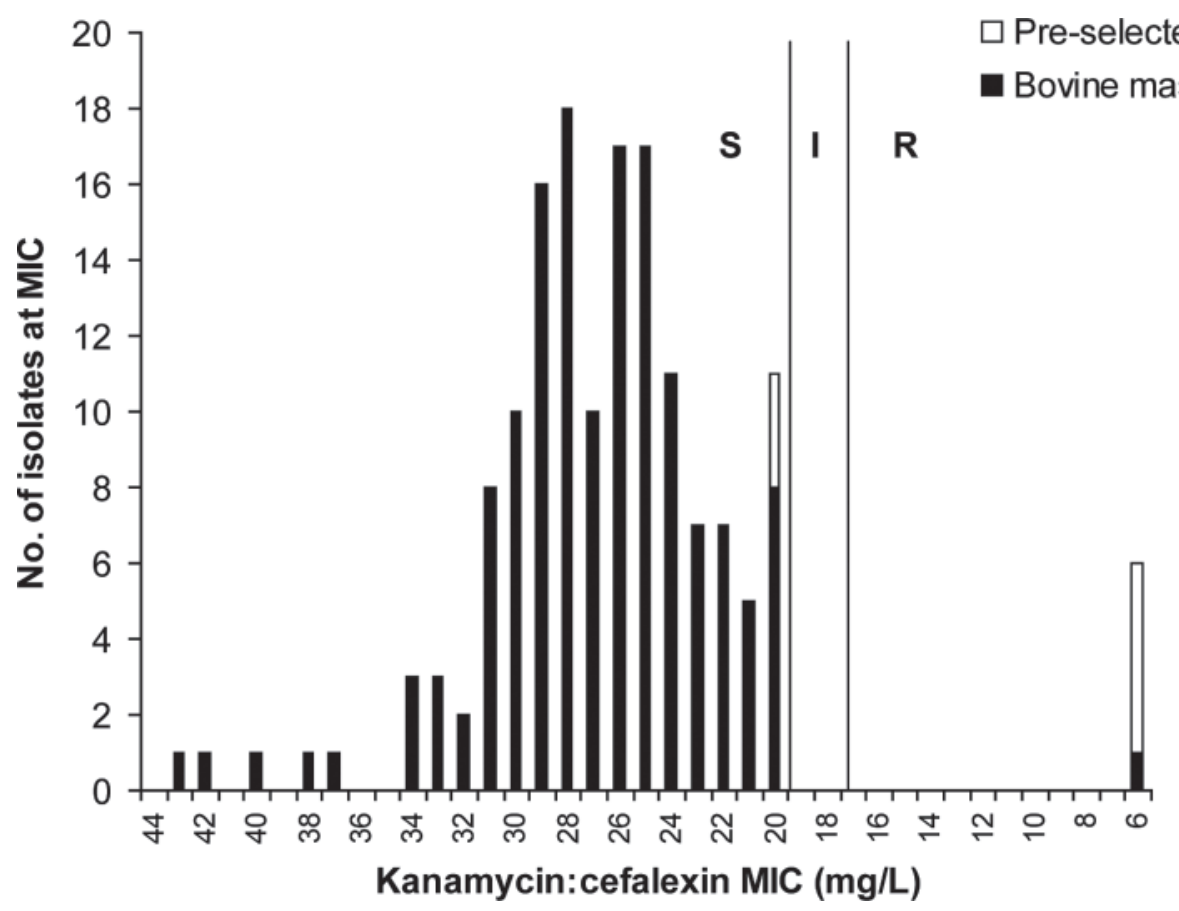

Figure 2. Disk zone distribution of kanamycin $(30 \mu \mathrm{g})$ in combination with cefalexin $(30 \mu \mathrm{g})$ against wild-type bovine mastitis CNS isolates and a subset of CNS isolates preferentially selected for resistance to kanamycin, cefalexin, or both. Applied interpretive criteria were those published by Pillar et al. (2009). $\mathrm{S}=$ susceptible, $\mathrm{I}=$ intermediate, $\mathrm{R}=$ resistant.

yet determined by applying the appropriate cut-off value in a defined phenotypic test system. Turnidge et al. (2006) described how interest in describing MIC distributions in a quantitative manner emerged during the process of European harmonization of breakpoints. In that process, it was agreed that the need existed

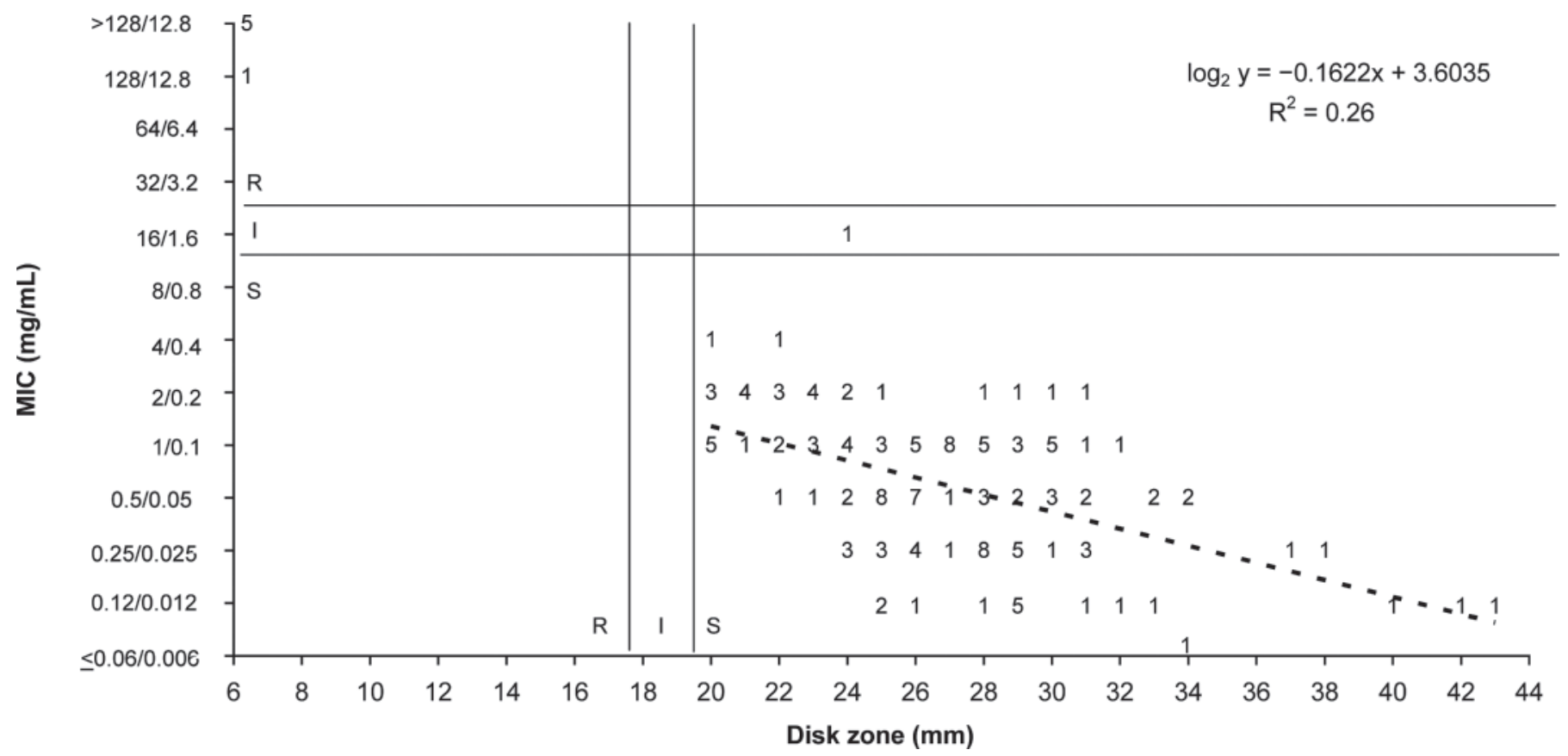

Figure 3. Broth microdilution MIC versus disk diffusion zone size correlation for all evaluated CNS. Applied interpretive criteria were those published by Pillar et al. (2009). $\mathrm{S}=$ susceptible, $\mathrm{I}=$ intermediate, $\mathrm{R}=$ resistant. 
to define wild-type MIC and set values (epidemiological cut-off values) that would discriminate wild-type strains from strains with acquired resistance mechanisms. These cut-off values would serve as a foundation for the laboratory detection of acquired resistance (decreased susceptibility) and for monitoring resistance development. Additionally, the European process for determining MIC breakpoints includes a step in which tentative breakpoints are checked against defined wildtype MIC distributions to ensure that breakpoints do not divide MIC distributions of target microorganisms (Kahlmeter et al., 2003; Kahlmeter and Brown, 2004). It is important to emphasize that wild-type distributions are species-specific and not considered to change over time (Kahlmeter et al., 2003); however, there can be some utility in describing the wild-type distribution for a group of pathogens implicated in disease. The data from this study describe the wild-type population of coagulase-negative mastitis pathogens and show that they are bounded by a MIC of 4/0.4. The data fall within the breakpoints proposed by Pillar et al. (2009) and, as such, meet the requirement that clinical breakpoints should not divide the wild-type distribution of important pathogens (Kahlmeter et al., 2003).

\section{CONCLUSIONS}

Our data illustrate that bovine mastitis isolates of CNS from Europe show a high degree of susceptibility to the kanamycin:cefalexin combination, with minimal resistance to either agent alone. The use of the available kanamycin and cefalexin combination disk for testing the susceptibility of bovine mastitis isolates of Staph. aureus, Strep. uberis, and E. coli, is also reliable for use in the testing of CNS, as disk results correlated with broth MIC. Furthermore, the interpretive criteria published for interpreting broth and disk results for this combination can be applied when testing CNS, as minimal error rates were detected when using these criteria.

\section{ACKNOWLEDGMENTS}

This study was sponsored by Boehringer Ingelheim Animal Health GmbH (Ingelheim, Germany).

\section{REFERENCES}

Bywater, R., P. Silley, and S. Simjee. 2006. Antimicrobial breakpointsdefinitions and conflicting requirements. Vet. Microbiol. 118:158159 .
CLSI. 2009. Methods for Dilution Antimicrobial Disk and Dilution Susceptibility Tests for Bacteria Isolated from Animals: Approved Standard (document M31-A3). 3rd ed. Clinical and Laboratory Standards Institute (CLSI), Wayne, PA.

CLSI. 2011. Performance Standards for Antimicrobial Susceptibility Testing; 21st Informational Supplement. M100-S21. Clinical and Laboratory Standards Institute (CLSI), Wayne, PA.

Ganiere, J. P., and L. Denuault. 2009. Synergistic interactions between cefalexin and kanamycin in Mueller-Hinton broth medium and in milk. J. Appl. Microbiol. 107:117-125.

Gillespie, B. E., S. I. Headrick, S. Boonyavatra, and S. P. Oliver. 2009. Prevalence and persistence of coagulase-negative Staphylococcus species in three dairy research herds. Vet. Microbiol. 134:65-72.

Kahlmeter, G., D. F. Brown, F. W. Goldstein, A. P. MacGowan, J. W. Mouton, A. Österlund, A. Rodloff, M. Steinbakk, P. Urbaskova, and A. Vatopoulos. 2003. European harmonization of MIC breakpoints for antimicrobial susceptibility testing of bacteria. J. Antimicrob. Chemother. 52:145-148.

Kahlmeter, G., and D. F. J. Brown. 2004. Harmonization of antimicrobial breakpoints in Europe-Can it be achieved? Clin. Microbiol. Newsl. 26:187-192.

Kronvall, G. 2010. Normalized resistance interpretation as a tool for establishing epidemiological MIC susceptibility breakpoints. J. Clin. Microbiol. 48:4445-4452.

Magiorakos, A. P., A. Srinivasan, R. B. Carey, Y. Carmeli, M. E. Falagas, C. G. Giske, S. Harbarth, J. F. Hindler, G. Kahlmeter, B. Olsson-Liljequist, D. L. Paterson, L. B. Rice, J. Stelling, M. J. Struelens, A. Vatopoulos, J. T. Weber, and D. L. Monnet. 2011. Multidrug-resistant, extensively drug-resistant and pandrug-resistant bacteria: An international expert proposal for interim standard definitions for acquired resistance. Clin. Microbiol. Infect. http://dx.doi.org/10.1111/j.1469-0691.2011.03570.x.

Maneke, E., A. Pridmore, L. Goby, and I. Lang. 2011. Kill rate of mastitis pathogens by a combination of cefalexin and kanamycin. J. Appl. Microbiol. 110:184-190.

Pillar, C. M., L. Goby, D. Draghi, P. Grover, and C. Thornsberry. 2009. Evaluating the in vitro susceptibility of bovine mastitis pathogens to a combination of kanamycin and cefalexin: Recommendations for a disk diffusion test. J. Dairy Sci. 92:6217-6227.

Schukken, Y. H., R. N. González, L. L. Tikofsky, H. F. Schulte, C. G. Santisteban, F. L. Welcome, G. J. Bennett, M. J. Zurakowski, and R. N. Zadoks. 2009. CNS mastitis: Nothing to worry about? Vet. Microbiol. 134:9-14.

Schwarz, S., P. Silley, S. Simjee, N. Woodford, E. van Duijkeren, A. P. Johnson, and W. Gaastra. 2010. Assessing the antimicrobial susceptibility of bacteria obtained from animals. Vet. Microbiol. 141:1-4.

Thorberg, B.-M., M.-L. Danielsson-Tham, U. Emanuelson, and K. Persson Waller. 2009. Bovine subclinical mastitis caused by different types of coagulase-negative staphylococci. J. Dairy Sci. 92:4962-4970.

Turnidge, J., G. Kahlmeter, and G. Kronvall. 2006. Statistical characterization of bacterial wild-type MIC value distributions and the determination of epidemiological cut-off values. Clin. Microbiol. Infect. 12:418-425

Zadoks, R. N., and J. L. Watts. 2009. Species identification of coagulase-negative staphylococci: Genotyping is superior to phenotyping. Vet. Microbiol. 134:20-28.

Zhang, S., and C. W. Maddox. 2000. Cytotoxic activity of coagulase-negative staphylococci in bovine mastitis. Infect. Immun. 68:1102-1108. 